\title{
Tratamiento Agresivo en el Aborto Septico
}

\author{
Dr. Saulo Muñoz Delgado - Dra. Juanita G. de Pasmín \\ Dr. Reinaldo Mora Restrepo - Dr. Humberto Caicedo Perea
}

Clínica de Maternidad de Cali

\footnotetext{
* Trabajo presentado en el IV Congreso Colombiano de Obstetricia y Ginecología. Noviembre - 1959 - Barranquilla.
}

La infección en el campo obstétrico sigue constituyendo una de las más numerosas y serias complicaciones y la causa de mayor mortalidadi en nuestro medio, a pesar del uso corriente de los antibióticos y de los recientes avances en el manejo de las complicaciones que surgen en estos casos. Además la utilización inadecuada e indiscriminada de los antibióticos ha hecho que las infecciones sean cada día de más difícil tratamiento.

En nuestro servicio el aborto incompleto representa el $20 \%$ de las pacientes hospitaliza las, lo que no solamente es un problema social de consideración sino que constituye una de las más altas erogaciones del presupuesto hospitalario.

Durante mucho tiempo se indicó el tratamiento conservador en el aborto séptico, pero en los últimos años algunas escuelas son partidarias de! tratamiento agresivo. La utilización de los antibióticos es posiblemente la causa de esta nueva orientación.

El tratamiento conservador ha sido preconizado de mucho tiempo atrás y en la actualidad encontramos que la mayoría de los autores lo sigue recomendando. Para Lull y Kimbrough (3)

Este trabajo ha sido financiado en su totalidad por la Casa Lilly, así como los trabajos de bacteriología y farmacología sobre el mismo tema. La parte bacteriológica estuvo a cargo del Dr. Miguel rracián quien presenta el trabajo titulado "Investigación" de 114 muestras de exudado uterino en casos de aborto séptico". La evaluación del Ilosone (R) utilizado en estos casos la ? resenta el Dr Alfonso Matallana en su trabajo. 
"el tratamiento del aborto séptico tiene que ser ante todo médico y de sostén a menos que la intensidad de la hemorragia obligue a evacuar inmediatamente el útero".

Eastman (6) opina que "el peligro del vaciamiento instrumental del útero en el aborto séptico estriba en la diseminación de la infección y gue el advenimiento de los antibióticos ha reducido este peligro pero no lo ha eliminado completamente". Solamente recomienda evacuación si la temperatura se normaliza por un período de 24-48 horas o en caso de hemorragia severa.

Greenhill (5) juzga que "la evacuación del útero se debe hacer solamente después de que la temperatura haya permanecido normal por 5 días, pero que generalmente puede hacerse antes de este tiempo".

Para Jaschke (1) "a la menor sospecha de que la enfermedad se haya transmitido al útero, así como en las complicaciones patentes de las inmediaciones del útero hay que prescindir de todo tratamiento activo".

Moragués (2) afirma que "ante el aborto complicado (sic) está contraindicada toda maniobra uterina. Debe esperarse a que desaparezca el estado febril".

Adair preconiza el tratamiento conservador y solamente interviene en caso de hemorragia abundante.

El tratamiento quirúrgico había sido preconizado tiempo atrás pero solamente en los últimos años se le está dando importancia, realizando controles bacteriológicos y administrando antibióticos específicos.

En 1922 Dietrich (9) presentó 10.000 casos de aborto séptico tratados activamente con curetaje instrumental y digital. La mortalidad para el tratamiento activo fue de $4.8 \%$ y de $3.1 \%$ para el tratamiento conservador.

Mahn (1957) (9) presenta pacientes tratadas con curetaje realizado entre las primeras 24 horas después del ingreso de la paciente al hospital. En el mismo año Tenney, Little y Wamsteker aconsejan el mismo tratamiento. 
El estudio cuidadoso del cuadro clínico en el aborto séptico permite observar la similitud que tiene con las infecciones procedentes de otro foco infeccioso. Esta olservación nos sugirió que el tratamiento debía estar dirigido a la supresión del foco séptico a partir del cual se producen bacteremias, septicemias y diseminación a otros órganos. La mayoría de los abortos incompletos se infectan, hecho que es más frecuente en el aborto provocado lo que induce a pensar que los causantes de la infección son los gérmenes de la flora vaginal transportados a la cavidad uterina, que encuentran en los restos ovulares un magnífico medio de proliferación. Es esta la razón para que en las infecciones por $\mathrm{Cl}$. welchii se aconseja la evacuación inmediata de la cavidad con el objeto de retirar el medio donde proliferan los microorganismos. Con este planteamiento se ha pensado que la evacuación inmediata de la cavidad uterina sería el tratamiento de elección. Para tratar las posibles diseminaciones se practican estudios bacteriológicos que permitan contrclar adecuadamente su complicación.

Presentamos una serie de casos de aborto séptico en los cuales se practicó de inmediato, al ingreso a la Clínica, la evacuación instrumental y un estridio comparativo con un grupo de pacientes en quienes se siguió tratamiento conservador o clásico, también llamado médico.

\section{MATERIAL Y METODOS}

Consideramos como "abortos sépticos" aquellos casos que al ingreso a la clínica presentaban un aborto incompleto con signos locales o generales de infección.

Llamamos "tratamiento conservador" aquel en que la paciente no se interviene hasta tanto que los signos generales de la infección hayan desaparecido, mediante la aplicación de antibióticos, quimioterápicos, ocitćcicos y medidas de sostenimiento.

El "tratamiento agresivo" consiste en la evacuación inmediata del útero al ingreso de la paciente a la Clínica con aplicación simultánea de antibióticos y demás medidas.

Revisamos todos los casos de aborto séptico que se presentaron en la Clínica de Maternidad durante los años 1956, 1957, 
1958 y del presente hasta el mes de Septiembre, con un total de 534 casos lo que da un valor porcentual del $20 \%$. Esta muestra se refiere únicamente a infecciones limitadas al útero y parametrios, grados I y II respectivamente de la clasificación de Falk (21).

A partir del año de 1957 iniciamos el tratamiento agresivo, tomando muestra de sangre para hemocultivo, frotis vaginal para examen microscópico directo y muestra de la cavidad uterina para cultivo y antibiograma. Luégo se iniciaba control leucocitario diario para observar la evolución. Inmediatamente después del raspado se inició tratamiento con antibióticos que consistió para un grupo de 34 pacientes en propionato de eritromicina (Ilosone (R) a una dosis que varió entre 1-2 gms. en las 24 horas, y para otro grupo de 448 pacientes en penicilina-estreptomicina en dosis promedio de 800.000 unidades y $1 \mathrm{gm}$. respectivamente en las 24 horas. En algunos pocos casos el tratamiento de penicilina-estreptomicina se complementó con el de sulfonamidas.

\section{TECNICA}

Para la toma de la muestra de la cavidad uterina se hace desla clasificación de Falk (21).

infección cuidadosa de la vagina y del cuello (jabón, agua y timerogal). Enseguida se hace la toma de material intrauterino con escobillón de algodón protegido por un tubo de vidrio de $5 \mathrm{~mm}$. de diámetro. Después de franquear el cérvix se hace sobresalir el escobillón del tubo y una vez tomada la muestra se regresa al tubo evitando de este modo la contaminación con el endocérvix y la vagina. (técnica modificada) Guilbeau y Schaub (22). La muestra se coloca en medio de transporte (23) y se envía para su estudio al Laboratorio.

\section{RESULTADOS}

1) Grupo conservador: En un total de 52 pacientes tratadas médicamente no se presentó ninguna muerte ni complicación de tener en cuenta. De éstas, 47 fueron clasificadas con infección grado I o sea el $90.5 \%$, y 5 o sea el $9.5 \%$ con grado II.

El promedio de permarencia fue de 4.9 días. 
De la permanencia total, 3.2 días correspcnden a la permanencia antes del raspado.

Durante su estadía se administraron en promedio 182 c.c. de sangre por paciente. La cantidad administrada fue menor de la que realmente era necesaria para colocar la paciente en condiciones óptimas.

Se utilizaron líquidos parenterales no solo para restablecer la volemia sino como vehículo para administrar ocitócicos, con un promedio de 855 c.c., por paciente.

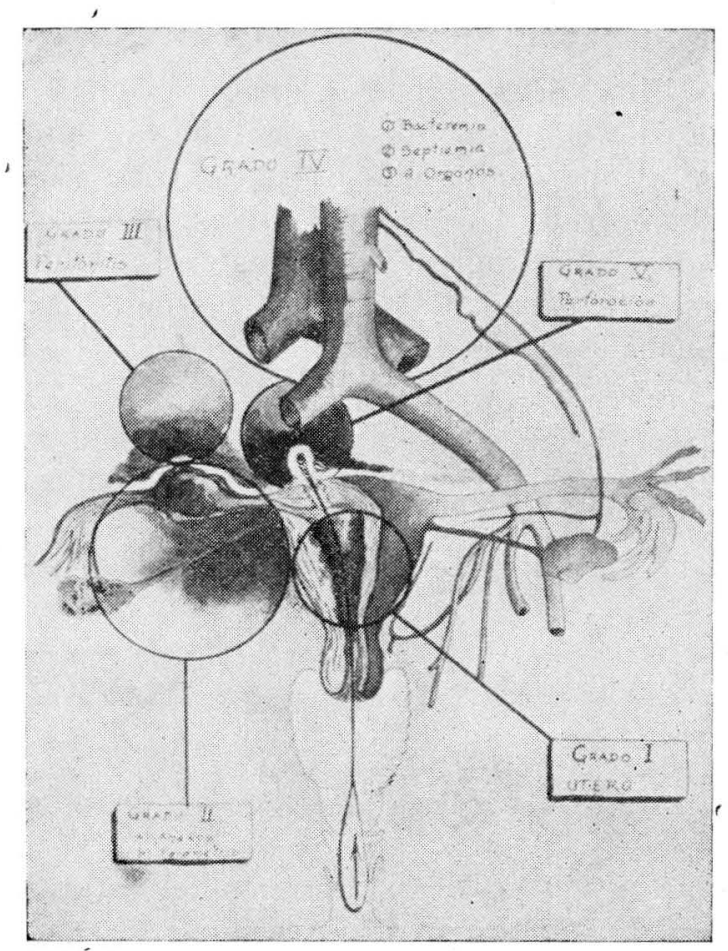

2) Grupo con tratamiento agresivo: Este grupo que comprende 482 pacientes lo hemos subdividido de acuerdo con el tratamiento en dos subgrupos que son: a) subgrupo a quienes se les hizo raspado inmediato sin comprobación bacteriológica, que contabiliza 400 casos: b) subgrupo en quienes se siguió el mismo tra- 
tamiento quirúrgico pero con comprobación bacteriológica y tratamiento a base de propionato de eritromicina (Ilosone $(R)$ ó penicilina-estreptomicina y sulfas. A estas pacientes se les practicó recuento leucocitario en forma diaria y se les hizo estudio completo de química sanguínea.

Subgrupo a) : ( $\sin$ cultivos). Este grupo comprende 400 pacientes, 364 fueron clasificadas con infección grado I, lo cual corresponde al $90 \%$ y con infección grado II, 36 que corresponden al $10 \%$. El promedio de temperatura al ingreso para este subgrupo fue de $38.2^{\circ} \mathrm{C}$. y el promedio de permanencia fue de 3.3 días.

Subgrupo b) · (comprobación bacteriológica y tratamiento con propionato de eritromicina ó penicilina-estreptomicina y sulfas) : Este subgrepo comprende 82 pacientes. Fueron clasificadas con infección grado I, 76 lo cual corresponde al $92.7 \%$ y 6 con infección grado II que representa al resto o sea $7.3 \%$. El promedio de temperatura para este subgrupo fue de $38.2^{\circ} \mathrm{C}$. y el promedio de permanencia fue de 4.3 días.

La diferencia de permanencia de 1 día entre los dos subgrupos se debió a que en el último se dejó a las pacientes por más tiempo para un más completo estudio bacteriológico.

\section{CONSIDERACIONES SOBRE LOS TRATAMIENTOS}

\section{CONSERVADOR Y AGRESIVO}

Los promedios de los dos subgrupos del tratamiento agresivo fueron $91.3 \%$ para el grado de infección I, 8.7\% para el grado de infección II; para los mismos grados del grupo conservador los promedios fueron $90.5 \%$ y $9.5 \%$ respectivamente. El promedio de temperatura fue de $38.2^{\circ} \mathrm{C}$. para el agresivo y de $38.1^{\circ} \mathrm{C}$. para el conservador, promedios que son muy similares y por lo tanto las muestras son comparables desde el punto de vista estadístico. El promedio de líquidos parenterales administrados fue de 845 c.c. para grupo do tratamiento conservador y 687 para 
el grupo de tratamiento agresivo. El promedio de sangre administrada fue de 202 c.c. para el grupo de tratamiento agresivo y 182 c.c. para el grupo de tratamiento conservador.

El promedio de permonencia para el grupo de tratamiento agresivo y para el de conservador fueron de 3.8 días y 4.9 días respectivamente. La diferencia de permanencia en el grupo de pacientes tratadas conservadora y agresivamente tienen significación estadística.

Recuento Leucocitario en 36 pacientes

\begin{tabular}{|c|c|c|}
\hline $\begin{array}{c}\text { Leucocitos } \\
\text { (miles) }\end{array}$ & Ingreso & Salida \\
\hline 10. & 5. & 9. \\
\hline 10. a 14.9 & 12. & 6 \\
\hline 15. & & \\
\hline & & \\
\hline
\end{tabular}


GRADOS DE INFECCION



A-Agresivo

B-Concervador

Wrado I \#ा Grado II 


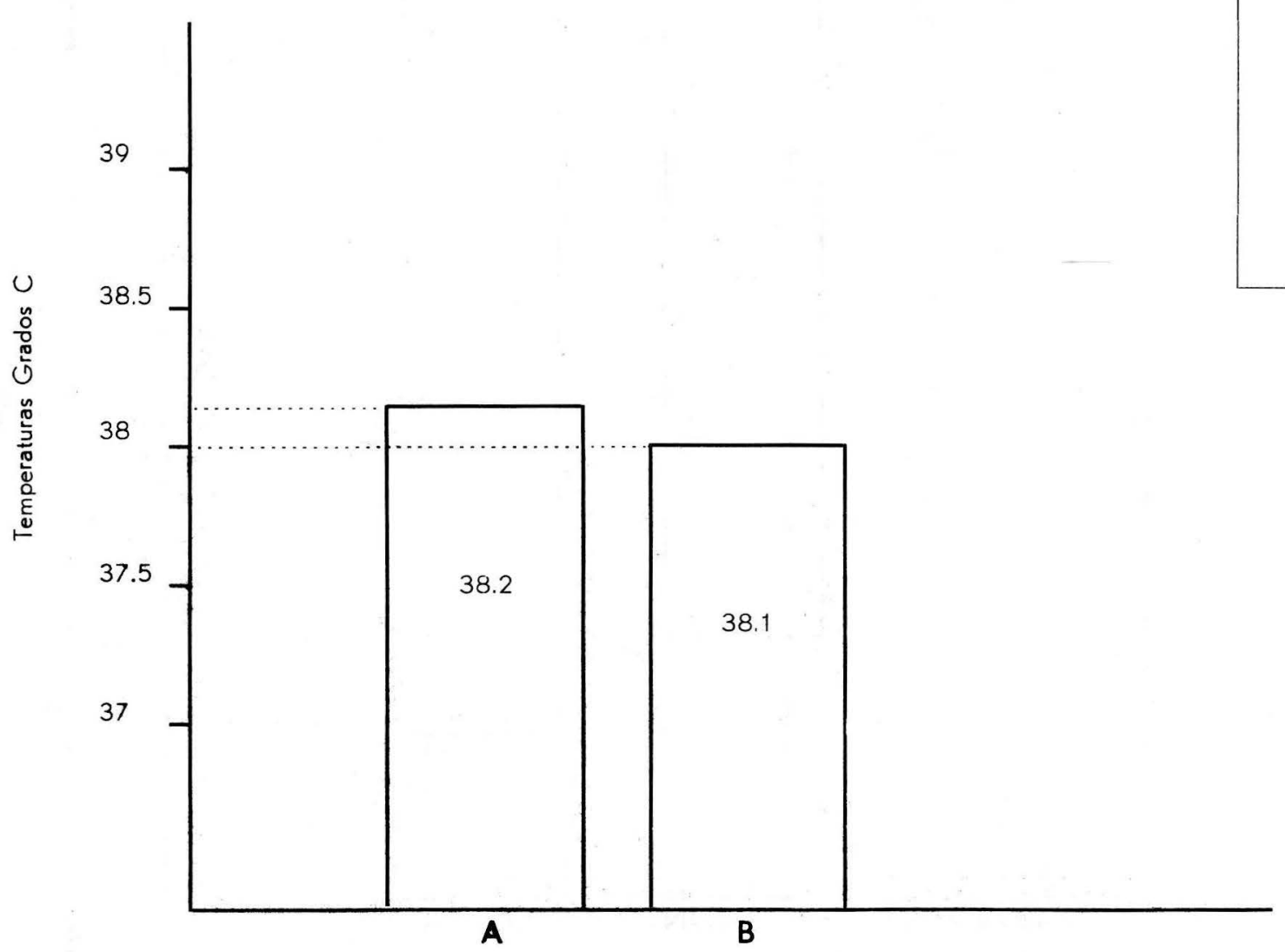

A-Agresivo

B-Conservador 
PROMEDIOS DE SANGRE EN C.C. POR PACIENTE

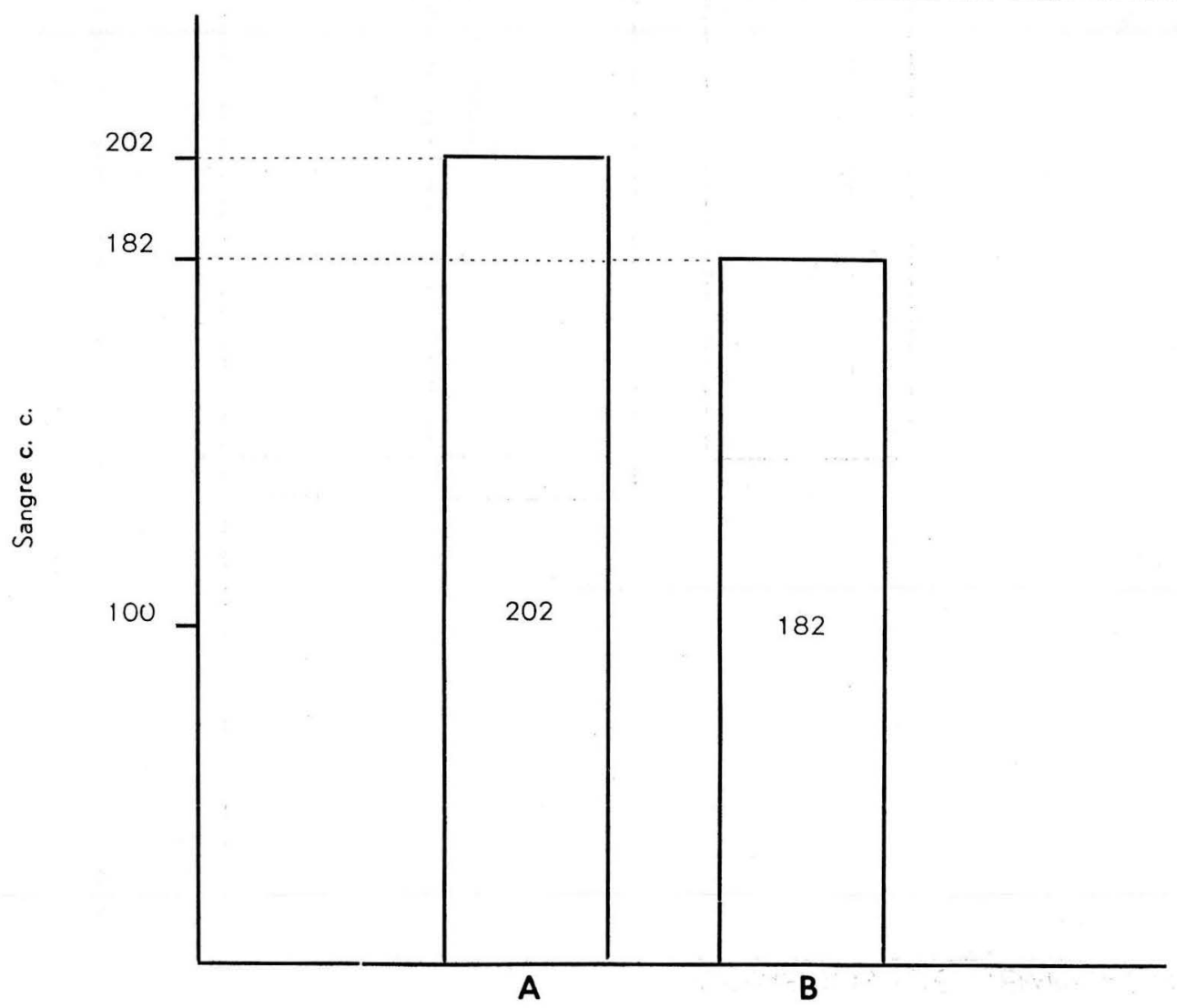

A-Agresivo

B.Conservador 
PROMEDIOS DE DEXTROSA EN C.C.

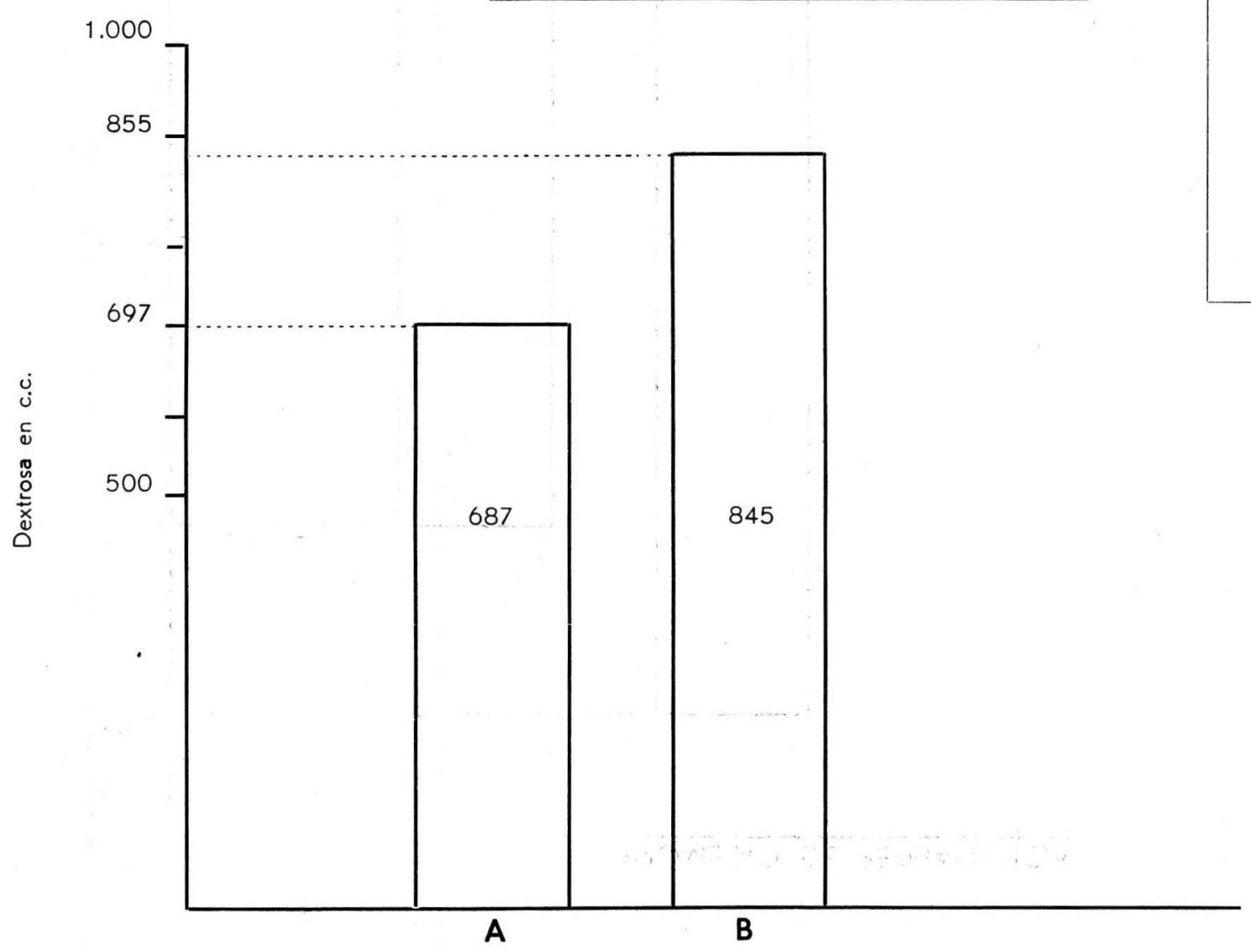

A-Agresivo

B-Conservador 
PROMEDIO DE PERMANENCIA

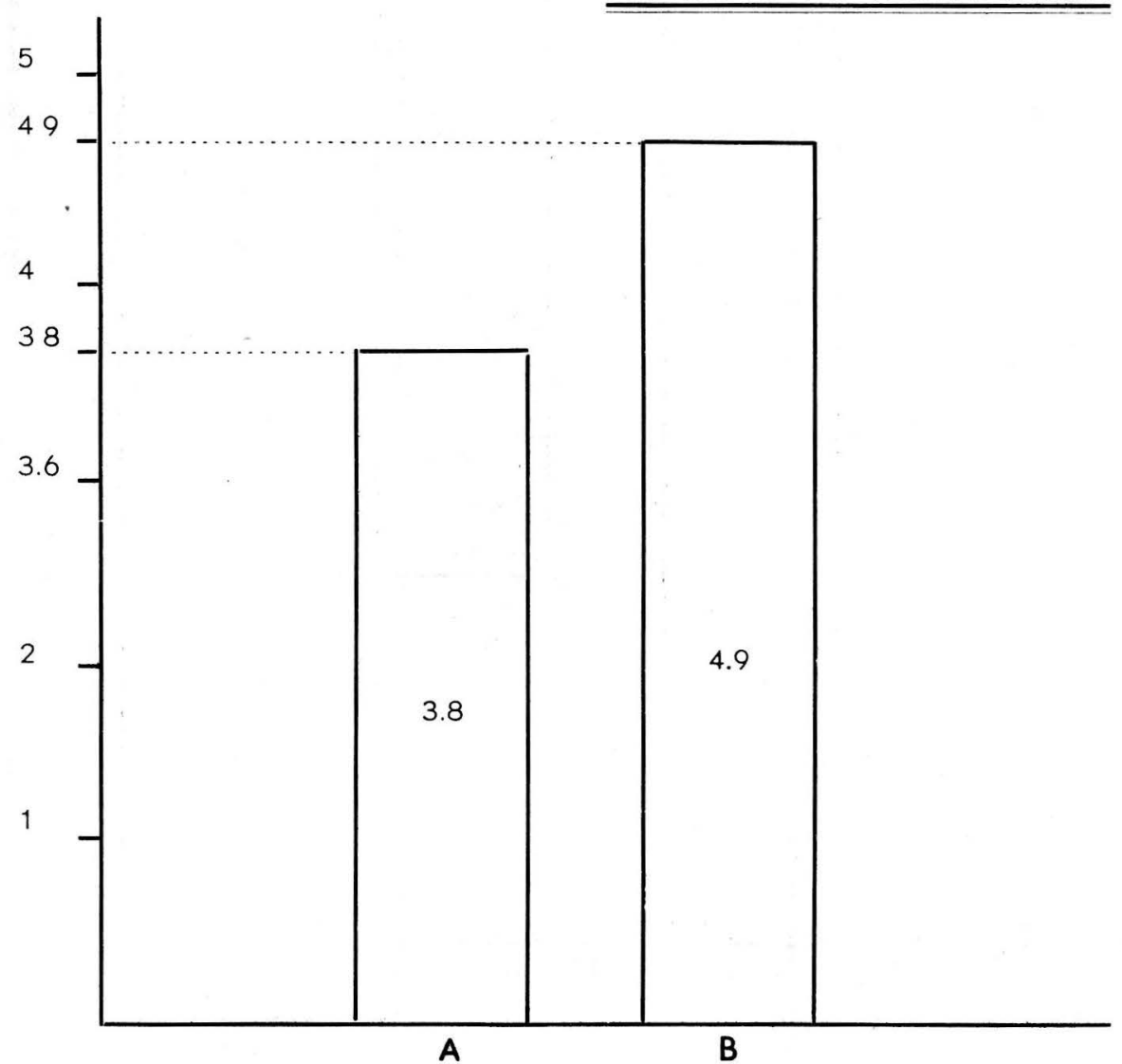

A- ${ }^{4}$ gresivo

B.Conservador 


\section{CUADRO COMPARATIVO TOTAL ENTRE TRATAMIENTO}

AGRESIVO Y CONSERVADOR

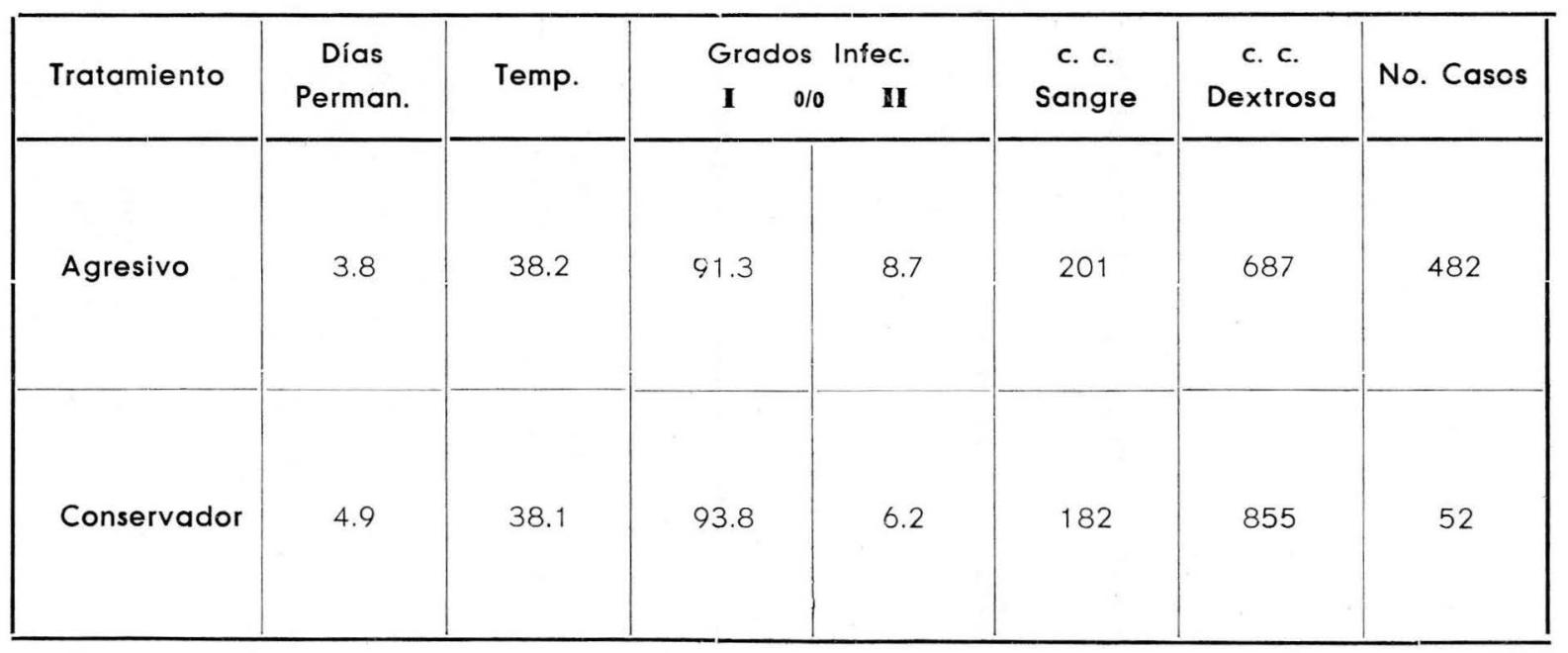




\section{COMENTARIOS}

La mayoría de las definiciones de aborto séptico se refieren a uno de los signos más prominentes del cuadro clínico. Así tenemos definiciones clínicas que consideran todos los abortos incompletos como sépticos o aquellos que presentan una serie de signos generales como dcshidratación, estado tóxico con taquicardia, lengua saburral, dolor abdominal etc.; para otros solo es séptico el aborto que se acompaña de fiebre (2-3-5-6) y un grupo en cambio sólo considera como séptico aquel en que se logra hacer comprobación en la cavidad uterina de gérmenes patógenos.

Estas definiciones sólo tienen en cuenta uno de los aspectos, por lo cual la sugerida por Ramsay, Brown y Manner (8) es más satisfactoria ya que los analiza conjuntamente. Estos autores consideran como sepsis uterina aquellos casos que presentan: a) signos generales de infección de los cuales la hiperpirexia y la taquicardia son lus más importantes; b) signos locales como dolor, subinvolución uterina y alteraciones de los loquios; c) confirmaciones bacteriológicas y hematológicas. Solamente con esta definición es posible clasificar los abortos asociados a Clostridium welchii como sépticos, pues es frecuente encontrar pacientes con sepsis muy severa, que no presentan fiebre (19).

Así mismo la designación dada al tratamiento "médico" la encontramos inaproniada puesto que en realidad es un tratamiento quirúrgico que se ha diferido por unos días, por lo que consideramos más adecuado proponer la denominación de "diferido" o "conservador".

La disparidad en los datos de mortalidad encontrados en el aborto séptico se debe a la falta de exactitud en la evaluación del grade de infección. Es necesario fijar normas respecto al grado de extensión de la infección. Diversos autores presentan clasificaciones que se refieren a la localización y a las vías de propagación (20) otros a los aspectos fisiopatológicos. Hemos tratado de ha- 
cerla más objetiva reuniendo en una sola principios patológicos y fisiopatológicos :

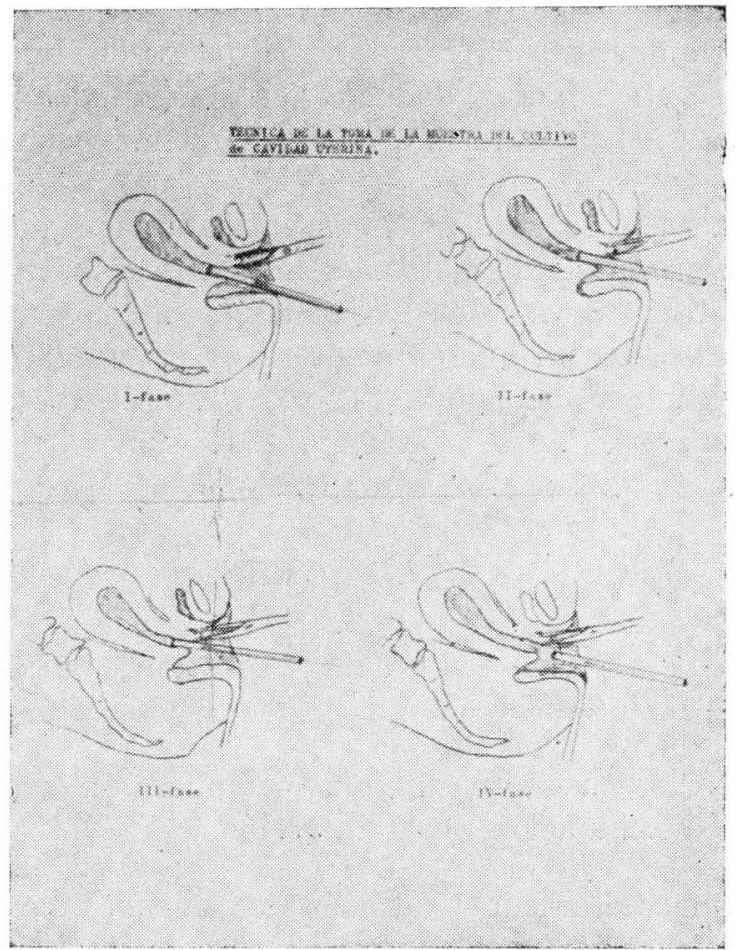

Grado I : Localizada exclusivamentte en el útero.

Grado II : Extensión a parametrios ó a trompas.

Grado III : Bacteremia. septicemia e invasión a otros órganos. Grado IV: Extensión a cavidad peritoneal.

Grado V : Perforación uterina.

Los principios existentes sobre la barrera leucocitaria y su poder de limitación e inactivación del foco infeccioso, han dado por mucho tiempo sustento al tratamiento conservador y es uno de los argumentos más poderosos que se ha presentado durante los últimos años frente al tratamiento agresivo.

Es curioso anotar que la descripción anatomopatológica de esta barrera hecha en 1914 siga siendo un hecho aceptado sin nin- 
guna comprobación de su papel de inactivadora de la infección. En publicaciones de los últimos años no nos ha sido posible encontrar ninguna descripción.

Es posible que esta barrera tuviera poder de limitación de la infección pero en la actualidad con las seguridades que brindan los antibióticos, no podríamos encontrarle la misma utilidad.

El aborto séptico es una de las entidades que más complicaciones puede presentar de las cuales la más frecuente es la extensión de la infección, ya sea a parametrios, anexos u otros órganos. En los casos en los que el agente es el Cl. welchii es frecuente la insuficiencia renal aguda (19-20). También es frecuente el colapso vascular lebido a septicemia (7). Sinembargo en nuestros casos no se presentaron complicaciones severas.

\section{CONCLUSIONES}

1) - El tratamiento propuesto es seguro ya que no hubo mortalidad en 482 casos.

2) - No se presentó ninguna complicación grave ni hubo evidencia de diseminación de la infección.

3) - Inmediatamente después del legrado desaparecieron los signos de infeeción y disminuyó la leucocitosis.

4) - El promedio de permanencia fue de 3.8 días, que es menor al del tratamiento conservador que fue de 4.9 días.

5) - Consideramos el tratamiento agresivo en el aborto séptico de elección en las infecciones grado I y II.

\section{BIBLIOGRAFIA}

1 JASCHKE, R. TH. Tratado de Obstetricia. Editorial Labor S. A., Barcelona, Madrid, etc. 1954. p. 584.

2 MORAGUES, J. Clínica Obstétrica. Librería y Editorial "El Ateneo", Buenos Aires, 1945.

3 LULL, C. B., and KIMBROUGH. R. A. Clinical Obstetrics J. B. Lippincott Comprany. Philadelphia, London, Montreal, 1953, p. 260. 
4 HOLLAND. E. and BOUR.NE, A. British obstetrics and Gynecological Practice. I. A. Davis Company, Philadelphia, 1955, p. 342-47.

5 GREENHILl, j. P. Obstetrics. W. B. Saunders Company, Philadelphia and London, 1955, p. 448-51.

6 EASTMAN, N. J. WILLIAMS. Obstetrics. Appleton Century Crofts, New York. 1956, 537.39.

7 STUDDIFORD, W. E., WATKINS G.: Placental bacteremia: significant finding in septic abortion accompanied by vascular collapse. American J. of Obst. and Gynec. 71: 842-858, 1956.

8 RAMSAY, A. M., BROWN, E. H., MANNER S. M.: Investigation and treatment of septic abortion. Brit. M. - ?: $1.239-1.243,1955$.

9 MAHN, E. Septic Abortion problems in Chile. Journal of the American Medical Women's assuciation, 12: 99-104, 1957.

10 TURKSOY, NURAN. The management of infected abortion. Am Journal of Obst. and Gynec. 13: 399-401, 1955.

11 TENNEY, B., LiTTLE, A. B. and WAMSTEKER E. Septic abortion. The New England Journal of Medicine, 257: 1.022-25, 1957.

12 WISE, R. I., SHAFFER, J. M., and SPINK, W. W. The sindrome of vascular collapse due to Gram negative bacteria: its management with L. norepinefrine and antibiotics. The Journal of Laboratory and Clini al Medicine, 40: 961, 1952.

13 BROWN, T. K. and HUNT, G. A. Bacteriologic study of five hundred consecutive abortions, with treatment and results. American Journal of Obst. and Gynec. 32: 804-813, 1936.

14 DAVIS, A. Two thousand six hundred and sixty five cases of abortion: Clinical survey. Brit. M. J. 20: 123-130, 1950.

15 DE ALVAREZ, R. R. and WOLTER, D. F. Management of postabortal sepsis and acute renal faillure due to clostridium welchii; Obstetrics and Gynecology, 11: 280-289, 1958.

16 MULE, G. and Mc CALL, M. L. The infected abortion. Clinical Obstetrics and Gynecology. 2: 87, 1959.

17 JOHNSON, C. A., BROWNER, D., SKILES, W. V., and CAIN, J. R. The non cperative treatment of inevitable and incomplete abortion. American Journal of Obst. and Gynec., 68: 576, 1954. 
18 FRENCH, T. A. Postabortal sepsis due to clostridium welchii simulating traumatic perforación of the uterus. American Journal of Obst. and Gynec. 73: 1.094, 1957.

19 MUÑOZ, S., MORA R, ESCOBAR J. Observaciones clínicas sobre la gangrena gaseosa del útero. Trabajo presentado ante el VI Congreso Médico Nacional (Bogotá, D. E. Julio 1959). En prensa.

20 MUÑOZ S. y MORA R. Insuficiencia renal aguda ó Necrosis tubular aguda en Obstetricia. Rev. Col. de Obst. y Ginec. 9: 485, 1958.

21 FALK, H. C. and BLINICK, G. Management of post-abortal peritonitis. American Journa! of Obst. and Gynec. 54: 314-320, 1957.

22 GUILBEAU, J. A. and SCHAUB, I. Uterine culture technic: simple method for avoinding contamination by cervical and vaginal flora. Am. J. Obst. y Gynec. 58: 407, 1959.

23 STUART R. D., Pub. Health Rep. 74: 431-438, 1959.

24 McKAY, D. G., JEWETT, G. I. and REID D. E. American Journal of Obst. and Gynec. 78: 546, 1959. 